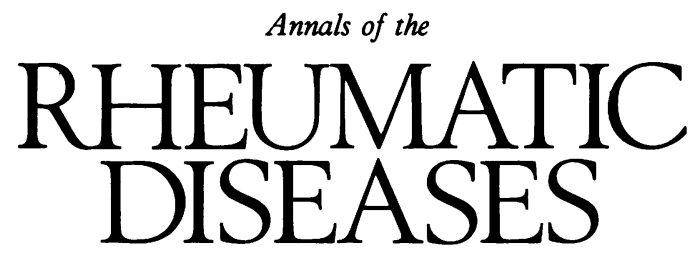

Leaders

\title{
Urticarial vasculitis and syndromes in association with connective tissue diseases
}

Urticarial vasculitis is now recognised as a distinct intity comprising urticaria-like lesions which are categorised histopathologically by leucocytoclastic vasculitis. In association with connective tissue diseases it is most commonly seen complicating systemic lupus erythematosus ${ }^{1}$ and, less often, Sjögren's syndrome. ${ }^{2}$ An editorial in the British Medical fournal in 1983 posed interesting questions about the relation between urticarial vasculitis and systemic lupus erythematosus, briefly discussing the chronic urticaria-angioedema syndromes as well as the simple chronic urticarias. ${ }^{3}$ These relations are still open to question and difficult to understand today, some eight years later. It is, however, abundantly clear, that a spectrum of clinical manifestations of urticarial vasculitis exists, occurring in patients who exhibit uncomplicated skin lesions only and ranging to those in whom the vasculitis is complicated by a systemic illness, often severe.

The coexistence of urticaria, angioedema/abdominal pain, and arthralgias has been well documented in patients with no evidence of a defined connective tissue disorder. These have recently been termed the AHA syndrome (arthralgias, arthritis (A), hives (H), angioedema (A)). An asymmetrical polyarthritis exists and it seems that symptoms might be precipitated by emotional stress, anxiety, exercise, and excessive alcohol ingestion. ${ }^{4}$ These patients may, indeed, form part of the same group recently reported by Pasero et al, ${ }^{5}$ suffering from the 'urticaria/arthritis syndrome', except that the latter patients did not have angioedema and all were shown to be B51 antigen positive. Arthralgias/arthritis in any event are not uncommon in association with the simple urticarias, and this combination has previously been reported. ${ }^{6}$ A study recently completed at St Thomas's Hospital included all patients with urticarial vasculitic lesions over a five year period. ${ }^{7}$ A different spectrum of disease patterns from those found in patients recently reported from the St Johns dermatology centre was evident. ${ }^{8}$

The diagnosis of urticarial vasculitis is essentially both clinical and histopathological. The condition is more frequently being recognised in association with connective tissue disease in rheumatology clinics today, and far fewer patients are being referred to dermatology centres for diagnosis or treatment, or both. It has also now become clear that treatment of the condition depends to a large extent on the nature of the underlying disease. Local treatment seems to be quite useless except for the symptomatic relief of the intense burning often felt at the site of the lesions.

The lesions vary from simple urticarial weals to 'giant' urticaria, accompanied in some by erythema multiforme-type lesions, purpura, or bullous lesions. They may last for several days, occurring in crops, or may be more or less permanent in some patients lasting for many weeks, months, or even years in a minority, with minor exacerbations and regression of the lesions. Some patients in the St Thomas's series complained of symptoms for as long as 23 years.

Patients with systemic lupus erythematosus may develop rashes which may closely resemble simple urticaria, or which may be erythema multiforme-like and accompanied by a strong urticarial element, referred to as 'urticated' by dermatologists. Angioedema/abdominal pain may accompany these lesions. Although sometimes occurring with episodes of lupus activity, this is by no means true in all patients as recurrent, mild eruptions may punctuate the course of the systemic disease with little or no evidence of clinical or serological activity. The distribution of the lesions bears no relation to the typical vasculitic rash seen with systemic lupus erythematosus or other recognised connective tissue disorders-for example, the fingertips, nail folds, knuckles, elbows, knees, etc. The aetiopathogenesis of urticarial vasculitis may be different from classical vasculitis and the lesions may not have the same prognostic significance as non-urticarial vasculitic lesions, in that they are not often complicated by severe local or systemic vasculitic organ disease.

The serum complement concentrations may be low, either because of a C4 null allele or because of complement activation, and may also be associated with increases of circulating immune complexes or cryoglobulinaemia, or both. The hypocomplementaemia may be episodic, and systemic symptoms may precede the hypocomplementaemia by several years.

Some investigators have looked at the association between skin lesions and genetic deficiencies of complement, and this subject has been well reviewed by Agnello. ${ }^{9}$ Rashes associated with genetic complement deficiencies are, however, usually of the lupus type, resembling those of subacute cutaneous lupus erythematosus or perhaps discoid lupus erythematosus. The predominant clinical feature is angioedema. A deficiency of the early components of complement may, however, predispose to a 'lupus-type' disease.

Urticarial vasculitis rashes and angioedema may be seen in those patients who do not fulfil four of the 1982 revised American Rheumatism Association criteria for the classification of systemic lupus erythematosus ${ }^{10}$ and who have been termed 'lupus-like' but who in reality have mild/moderate lupus, as well as in patients with 'mixed' connective tissue disease. Patients with Sjögren's syndrome or essential cryoglobulinaemia usually have a different pattern of skin lesions, which may have an urticarial element but are predominantly purpuric and are seen mainly over the legs. They are often precipitated by exercise and have been termed 'purpura hyperglobulinaemia/ anaphylactoid purpura'.

Urticarial vasculitis, arthralgias, myalgias, and angioedema may also be encountered in patients with 'primary' vasculitis. Other manifestations of systemic vasculitis may be prominent in these patients, such as episcleritis, uveitis, iridocyclitis, and, perhaps, retinal vasculitis. When the urticarial vasculitis is associated with severe hypocomplementaemia (particularly of $\mathrm{Clq}$, but also $\mathrm{C} 4, \mathrm{C} 2$, and $\mathrm{C} 3$ ) the term hypocomplementaemic urticarial vasculitis syndrome has been used. ${ }^{11-15}$ This syndrome is often accompanied by chronic obstructive pulmonary disease,${ }^{16}$ immune complex nephritis, ${ }^{17}$ and central nervous system complications, particularly pseudotumour 
cerebri. $^{1 / 2}$ is Rarely, patients with hypocomplementaemic urticarial vasculitis syndrome may progress to systemic lupus erythematosus. ${ }^{19}$

A group of patients with normocomplementaemic urticarial vasculitis/arthritis syndrome also exists. This was initially recognised by Sanchez et al, ${ }^{19}$ and several patients with this type of disorder have been identified in the St Thomas's series. This seeems not to be a lupus associated condition, but forms part of the primary vasculitis spectrum. Differences between this condition and hypocomplementaemic urticarial vasculitis syndrome are the absence of lowering of complement components and the generally milder systemic complications, particularly the absence of renal disease.

Urticarial vasculitic lesions may also appear with necrotising or granulomatous vasculitides-for example, with polyarteritis nodosa or Wegener's granulomatosis, but the predominant appearance is purpuric rather than urticarial.

What of the conditions associated with $\mathrm{Clq}$ esterase inhibitor to urticarial vasculitic lesions? A deficiency of $\mathrm{Cl}$ inhibitor, either genetic or acquired (for example, with lymphomas), leads to a deficiency of $\mathrm{C} 4$ and $\mathrm{C} 2$. The rashes in this condition are of the 'lupus' type, affecting the butterfly area of the face, and may be discoid or subacute cutaneous lupus erythematosuslike. ${ }^{20-22}$ Angioedema is the clinical hallmark of this condition, and urticarial vasculitis usually does not occur. Treatment with danazol (an impeded oestrogen) in this condition has resulted in clearance of the skin lesions as well as elimination of photosensitivity.

The existence of IgG antibodies to $\mathrm{Clq}$ in hypocomplementaemic urticarial vasculitis syndrome has been recently confirmed by Wisnieski and Naff. ${ }^{23}$ Precipitins, $7 \mathrm{~S}$ as well as $>19 \mathrm{~S}$, had been found earlier by Agnello et al. ${ }^{24}$ The existence of $\mathrm{Clq}$ antibodies is not unique to patients with this syndrome, however, as they have also been shown in patients with systemic lupus erythematosus without any vasculitic manifestations. ${ }^{25-27}$

The treatment of urticarial vasculitis is, to say the least, problematical. There is usually no response to antihistamines alone, indicating that urticarial vasculitis is not caused by mast cell-histamine mechanisms as is simple urticaria. Parenteral high dose oral steroids of intravenous 'pulse' cyclophosphamide may be effective in some, but repeated 'pulses' may be necessary to maintain a satisfactory response. Too rapid a reduction in steroid dosage may precipitate a 'flare'. The use of azathioprine is usually without effect. Antimalarial drugs (mepacrine/hydroxychloroquine) ${ }^{28} 29$ may be effective as may colchicine. $^{30} 3131 \mathrm{a}$ The use of dapsone is often precluded by side effects, but this compound may be effective in selected cases. ${ }^{32}{ }^{33}$ Non-steroidal anti-inflammatory drugs are generally ineffective, but naproxen, benoxaprofen, or indomethacin have been successfully used in a few patients. ${ }^{34}$ Such drugs may be more effective when combined with an $\mathrm{H} 1$ receptor antagonistfor example, Phenergan. Intravenous gammaglobulin treatment has not yet been evaluated. ${ }^{35}$ The use of the new combination monoclonal antibody Compath 1-H combined with a monoclonal antibody directed against CD4 cells has recently been successfully used in a patient with cutaneous vasculitis and provides us with most exciting future prospects for treatment of this notoriously intractable condition. ${ }^{36}$

Division of Rheumatology and

RONALD A ASHERSON

Connective Tissue Diseases,

St Lukes/Roosevelt Hospital Centre,

New York

NY 10019, USA

Department of Dermatology, University of Texas Southwestern Medical Centre,

Dallas,

Texas 75235 , USA
1 O'Loughlin S, Schroeter A L, Jordan R E. Chronic urticaria-like lesions in systemic lupus erythematosus. Arch Dermatol 1978; 114: 879-83.

2 Alexander E L, Arnett F C, Provost T T, Stevens M B. Siögren's syndrome: association of anti-Ro (SSA) antibodies with vasculitis, haematological association of anti-Ro (Si) antibodies with vasculitis, haematological 3 abnormalities and serologic hyperactivity. Ann Intern Med

4 McNeil D J, Kinsella T D, Crawford A-M, Fritzler M J. The AHA syndrome: arthritis, hives and angioedema. Rheumatol Int 1987; 7: 277-9. syndrome: arthritis, hives and angioedema. Rheumatol Int 1987; 7: 277-9.
Pasero G, Olivieri I, Gemignani G, Vitale C. Urticaria/arthritis syndrome: report of four B51 positive patients. Ann Rheum Dis 1989; 48: 508-11.

6 Molloy P J, Conoso J J, Gelfard J A. Rheumatic manifestations of urticaria and angioedema. Arthritis Rheum 1987; 30: S8-15N.

7 Asherson R A, D'Cruz D, Stevens C, et al. Urticarial vasculitis as seen in a connective tissue disease clinic. Patterns, presentations, and treatment. Semin Arthritis Rheum 1990; 20: 285-96.

8 Aboubaker J, Greaves M W. Urticarial vasculitis. Clin Exp Dermatol 1986; 11: 436-44.

9 Agnello V. Lupus diseases associated with hereditary and acquired deficiencies of complement. Springer Semin Immunopathol 1986; 9: 161-78.

10 Tan E M, Cohen A S, Fries J F, et al. The 1982 revised criteria for the classification of systemic lupus erythematosus. Arthritis Rheum 1982; 25: 1271-7.

11 Sissons J G P, Peters D K, Williams D G, Boulton-Jones J M, Goldsmith H J. Skin lesions, angio-oedema and hypocomplementaemia. Lancet 1974; ii: 1350-2.

12 Feig P V, Soter N A, Yager H M, Caplan L, Rosen S. Vasculitis with urticaria, hypocomplementemia, and multiple system involvement. $\mathcal{F A M A}$ 1976; 236: 2065-8.

13 McDuffie F C, Sams W H Jr, Maldonado J E, Andreini P H, Conn D L, Samayoa E A. Hypocomplementaemia with cutaneous vasculitis and arteritis. Mayo Clinic Proc 1973; 48: 340-8.

14 Gammon W R, Wheeler C E Jr. Urticarial vasculitis. Arch Dermatol 1979; 115: 312-7.

15 Zeiss C R, Burch F X, Marder R J, Furey N L, Schmid F R, Gewurz H. A hypocomplementaemic vasculitic urticarial syndrome: report of four new

16 Schwartz H R, McDuffie F C, Black L F, Schroeter A L, Conn D L. Hypocomplementaemic urticarial vasculitis: association with chronic obstructive pulmonary disease. Mayo Clin Proc 1982; 57: 231-8.

17 Moorthy A V, Pringle D. Urticaria, vasculitis, hypocomplementaemia and immune complex glomerulonephritis. Arch Pathol Lab Med 1982; 106: 68-70.

18 Coca A, Font J, Herrero C, Gonsalez M A, Ingelmo M. Hypocomplementaemic vasculitis and systemic lupus erythematosus. F R heumatol 1987; 14: 854-5.

19 Sanchez N P, Winkelmann R T, Schroeter A L, Dicken C H. The clinical and histopathological spectrums of urticarial vasculitis: study of forty cases. histopathological spectrums of urticaria

20 Donaldson V H, Rosen F S. Action of complement in hereditary angioneurotic oedema: the role of Clq esterase. $\mathcal{F}$ Clin Invest 1964; 43: 2204-13.

21 Donaldson V H, Hess E V, McAdams A J. Lupus erythematosus-like disease in three unrelated women with hereditary angioneurotic oedema. Ann Intern Med 1977; 86: 312-3.

22 Kohler P F, Percy J, Campion W M, Smyth C J. Hereditary angio-oedema and "familial" lupus erythematosus in identical twin boys. Am f Med 1974; 56: 406-11.

23 Wisnieski J J, Naff G B. Serum IgG antibodies to Clq in hypocomplementaemic urticarial vasculitic syndrome. Arthritis Rheum 1989; 32: 1119-27.

24 Agnello V, Koppler D, Eisenberg J W, Winchester R J, Kundel H G. Clq precipitins in the serum of patients with systemic lupus erythematosus and precipitins in the serum of patients with systemic lupus erythematosus and molecular weight types. $\mathcal{F}$ Exp Med 1971; 134 (suppl): 2285.

25 Uwatoko S, Aotsuka S, Okawa M, et al. Characterization of Clq binding IgG complexes in systemic lupus erythematosus. Clin Immunol Immunopathol 1984; 30: $104-16$

26 Antes V, Heinz H-P, Loos M. Evidence for the presence of autoantibodies to the collagen-like portion of Clq in systemic lupus erythematosus. Arthritis Rheum 1988; 31: 457-64.

27 Uwatoko S, Mannik M. Low molecular Clq binding immunoglobulin G in patients with systemic lupus erythematosus consists of autoantibodies to the collagen-like region of Clq. $\mathcal{F}$ Clin Invest 1988; 82: 816-24.

28 Curd J G, Zuraw B L. Efficacy of hydroxychloroquine treatment of urticarial vasculitis [abstract]. $\mathcal{F}$ Allergy Clin Immunol 1984; 73: 181.

29 Lopez L R, Davis K C, Kohler P F, Schocket A L. The hypocomplementaemic urticarial-vasculitis syndrome: therapeutic response to hydroxymentaemic urticarial-vasculitis syndrome: therapeutic

30 Wiles J C, Hansen R C, Lynch P J. Urticarial vasculitis treated with colchicine. Arch Dermatol 1985; 121 : 802-5

31 Werni R M, Schwartz T H, Gschnait F. Colchicine treatment of urticarial vasculitis. Dermatologica 1986; 172: $36-40$

3laAsherson R A, Buchanan N, Kenwright S, Fletcher C M, Hughes G R V. The normocomplementemic urticarial vasculitis syndrome-report of a case and response to colchicine. Clin Exp Dermatol. In press.

32 Mathews C N A, Saihin E M, Warin R P. Urticaria-like lesions associated with systemic lupus erythematosus; response to dapsone. $\mathrm{Br} \mathcal{F}$ Dermatol 1978; 99: 455-7.

33 Fortson J S, Zone J J, Mammond E, Groggel G C. Hypocomplementaemic urticarial vasculitis syndrome responsive to dapsone. $\mathcal{f}$ Am Acad Dermatol 1986; 15: 1437-42

34 Millns J L, Randle H W, Solley G O, Dicken C H. The therapeutic response of urticarial vasculitis to indomethacin. 7 Am Acad Dermatol 1980; 3: of urticar

35 Berkman S A, Lee M L, Gale R P. Clinical uses of intravenous immunoglobulin. Ann Intern Med 1990; 112: 278-92.

36 Mathieson P W, Cobbold S P, Hale G, et al. Monoclonal-antibody therapy in systemic vasculitis. $N$ Engl f Med 1990; 323: $250-4$ 